Société d'histoire de la révolution de 1848 et des

révolutions du XIXe siècle

$44 \mid 2012$

L'Italie du Risorgimento. Relectures

\title{
Strasbourg 1870, le récit du siège d'après le journal inédit d'Ernest Frantz, 15 juillet-28 septembre
}

introduction et commentaires d'Aline Bouche, David Bourgeois et MarieClaire Vitoux, Nancy, Éditions Place Stanislas, 2011, 240 p. ISBN :

978-2-35578-087-5. 25 euros.

\section{Olivier Berger}

\section{OpenEdition}

\section{Journals}

Édition électronique

URL : http://journals.openedition.org/rh19/4277

DOI : $10.4000 /$ rh 19.4277

ISSN : $1777-5329$

Éditeur

La Société de 1848

Édition imprimée

Date de publication : 30 septembre 2012

Pagination : 213-214

ISSN : 1265-1354

Référence électronique

Olivier Berger, «Strasbourg 1870, le récit du siège d'après le journal inédit d'Ernest Frantz, 15 juillet-28

septembre ", Revue d'histoire du XIXe siècle [En ligne], 44 | 2012, mis en ligne le 16 octobre 2012, consulté le 22 septembre 2020. URL : http://journals.openedition.org/rh19/4277 ; DOI : https:// doi.org/10.4000/rh 19.4277

Ce document a été généré automatiquement le 22 septembre 2020.

Tous droits réservés 


\section{Strasbourg 1870, le récit du siège d'après le journal inédit d'Ernest Frantz, 15 juillet-28 septembre}

introduction et commentaires d'Aline Bouche, David Bourgeois et MarieClaire Vitoux, Nancy, Éditions Place Stanislas, 2011, 240 p. ISBN :

978-2-35578-087-5. 25 euros.

\section{Olivier Berger}

\section{RÉFÉRENCE}

Strasbourg 1870, le récit du siège d'après le journal inédit d'Ernest Frantz, 15 juillet-28 septembre, introduction et commentaires d'Aline Bouche, David Bourgeois et MarieClaire Vitoux, Nancy, Éditions Place Stanislas, 2011, 240 p. ISBN : 978-2-35578-087-5. 25 euros.

Depuis une vingtaine d'années, la guerre franco-allemande suscite l'intérêt des historiens. Dans la continuité des travaux de Stéphane Audoin-Rouzeau, François Roth, Jean-François Lecaillon, Pierre Milza et Henri Ortholan, le présent livre participe au renouvellement historiographique en cours, ici dans une perspective culturelle ${ }^{1}$. Il s'agit de l'édition critique d'un témoignage sur le siège de Strasbourg, durant lequel la population civile constitue un enjeu pour l'assiégeant. L'auteur, républicain protestant, instruit et clairvoyant, relate de manière détaillée les ravages du siège sur le plan matériel mais aussi moral. Il cite les nombreux cas de mutilations de civils par les obus, la mitraille et les bombes incendiaires, et évoque la souffrance causée par la privation de nouvelles. Chaque jour a sa notice, accompagnée d'affiches, proclamations et autres documents d'époque. Le style est sobre, entraînant le lecteur au plus près du vécu des Strasbourgeois, ces derniers passant petit à petit de la confiance à l'abattement. Employé aux hospices civils de Strasbourg, Ernest Frantz partage peu leur défaitisme même si son expérience de garde national le confronte à la réalité quotidienne d'un 
siège difficile. Il accuse l'impéritie du régime impérial aussi bien que l'action des « cléricaux » qui auraient selon lui affaibli l'esprit des populations. À l'instar de nombre de ses contemporains, il pense que la République pourrait sauver la situation.

Le récit proposé par Ernest Frantz rend bien compte du caractère «totalisant $»^{2}$ de cette guerre, qui se situe à la charnière entre guerre d'Ancien Régime et conflit moderne, où la puissance de feu meurtrière doit emporter rapidement la décision. Par le bombardement aveugle des secteurs d'habitations, la destruction du Temple et de la Bibliothèque, la guerre prend un visage moderne, au sens où elle implique les civils. Ainsi, dans leur présentation, les éditeurs du volume mettent l'accent sur l'extrême brutalité du siège et les excès commis ; ils n'hésitent pas à parler, même si c'est avec une certaine prudence, de "crime de guerre». Ernest Frantz est conscient du haut niveau de violence. Les projectiles sont dévastateurs : «Beaucoup [d'obus] sont remplis d'une composition incendiaire qu'il est impossible d'éteindre avec de l'eau et qui brûle pendant dix minutes » (p. 142). D'autres, pesant de 25 à $75 \mathrm{~kg}$, sont remplis de balles qui se dispersent. Et les bombardements nocturnes ont pour objectif de démoraliser les civils afin qu'ils demandent à leurs gouvernants une capitulation.

Le récit est accompagné de chapitres qui proposent des mises au point utiles sur l'origine du conflit, l'auteur du Journal et les principaux personnages cités. En outre, une chronologie met en parallèle les événements de la guerre et ses épisodes régionaux, et une très riche iconographie, issue de fonds publics, complète le volume. Une série de photographies d'époque donne notamment à voir l'ampleur du bombardement. La bibliographie aurait mérité d'être un peu étoffée, notamment élargie, au-delà de Strasbourg et sa région, aux autres villes ayant eu à subir un siège en règle ${ }^{3}$. En résumé, ce livre est solidement construit et les éditeurs ont fait un beau travail en exhumant ce journal inédit du siège de Strasbourg ${ }^{4}$.

\section{NOTES}

1. Stéphane Audoin-Rouzeau, 1870, La France dans la guerre, Paris, Armand Colin, 1989 ; François Roth, La guerre de 70, Paris, Fayard, 1990 ; Jean-François Lecaillon, Les Français et la guerre de 1870, Paris, Giovanangeli, 2004 ; Pierre Milza, L'année terrible, Paris, Perrin, 2009 ; Henri Ortholan, auteur d'ouvrages sur les armées républicaines de l'Est, de la Loire et du Nord, aux éditions Giovanangeli. Plusieurs colloques sont à citer : Philippe Levillain et Rainer Riemenschneider [dir.], La guerre de 1870-71 et ses conséquences, Bonn, Bouvier Verlag, 1990; La guerre de 1870, $3^{e}$ colloque historique des bords de Marne, 18 septembre 2004, Le Perreux-sur-Marne ; 1870-1871, retour sur une guerre oubliée, 23 et 24 mars 2010, Musée de l'Armée, Paris ; Strasbourg-Belfort 1870/1871, de la guerre à la paix, 4 et 5 novembre 2011, Strasbourg et Belfort ; La guerre de 1870 dans l'Oise, journée d'études aux Archives de l'Oise, 5 novembre 2011; Les années 1870-1871 dans le Sud-Ouest atlantique, 25 novembre 2011, Bayonne, etc.

2. Expression de Jean-François Lecaillon, Les Français et la guerre de 1870..., op. cit., p. 206.

3. On pense notamment à Toul, Verdun, Phalsbourg, Belfort, Metz, et bien entendu Paris.

4. La lecture de cet ouvrage pourra être complétée par une visite virtuelle de l'exposition : «1870 Strasbourg brûle-t-il? », qui s'était tenue à Strasbourg, du 11 septembre au 10 décembre 2010 : 
http://www.musees.strasbourg.eu/sites_expos/stbg_1870/fr/index.php (page consultée le 17 janvier 2012). 